\title{
Multi-Agent Based Hierarchical Hybrid Control for Smart Microgrid
}

\author{
Chun-Xia Dou and Bin Liu
}

\begin{abstract}
This paper studies the smart control issue for an autonomous microgrid in order to maintain the secure voltages as well as maximize economic and environmental benefits. A control scheme called as multi-agent based hierarchical hybrid control is proposed versus the hierarchical control requirements and hybrid dynamic behaviors of the microgrid. The control scheme is composed of an upper level energy management agent, several middle level coordinated control agents and many lower level unit control agents. The goals of smart control are achieved by designed control strategies. The simulations are given to demonstrate the effectiveness of proposed smart control for an autonomous microgrid.
\end{abstract}

Index Terms-Hybrid control, microgrid, multi-agent systems, smart control.

\section{INTRODUCTION}

$\mathbf{P}$ OWER generation has been seen an increased penetration of distributed generations (DGs) in recent times. The need of reliability as well as the pursuit of maximum economical and environmental benefits for DGs stimulates the creation of microgrid (MG). The MG has received increased attention as an effective means of integrating DGs into the electricity network, which is composed generally by confined cluster of loads, storage devices and small generators that so-called microsources. The autonomous network has the ability as single entity to work in both grid-connected and islanded modes of operation [1], [2].

Compared with traditional large power system, a MG is facing with more new challenges:

1. More complex components of system. Unlike large power system which has exclusively $50 / 60 \mathrm{~Hz}$ synchronous machines, a MG contains many kinds of distributed generations and distributed storage devices. The dynamic characteristics of each distributed unit differ from the others. Moreover, many of them are non- $50 / 60 \mathrm{~Hz}$ distributed energy resources (DERs). These DERs require power-electronic converter interfaces when they are connected into grid. However, such low-inertia time interfaces not only reduce overload capability of the system and make it more sensitive to disturbances, but also increase the complexity of system [3], [4].

Manuscript received March 09, 2012; revised June 30, 2012, August 23, 2012, October 11, 2012; accepted November 17, 2012. Date of publication January 21, 2013; date of current version May 18, 2013. This work is supported by the National Natural Science Foundation of China under Grant 51177142 and 61174075, the China Postdoctoral Science Foundation under Grant No. 2012T50019 and 20110490210, Hebei Provincial Natural Science Foundation of China No. F2012203063, and Hunan Provincial Natural Science Foundation of China No. 11JJ2038. Paper no. TSG-00100-2012.

C.-X. Dou is with the Institute of Electrical Engineering, Yanshan University, Qinhuangdao 066004, China (e-mail: cxdou@ysu.edu.cn).

B. Liu is with Department of Information and Computation Sciences, Hunan University of Technology, Zhuzhou 412008, China, and also with the Research School of Engineering, The Australian National University, Canberra 0200, Australia.

Digital Object Identifier 10.1109/TSG.2012.2230197
2. More complex hybrid dynamic behaviors. Compared with large power system, a MG usually appears more complex interactive hybrid dynamic behaviors. It is mainly because that many distributed generation units drive both continuous and discrete dynamic behaviors. On the one hand, their generating electricity complies with physical laws and displays continuous dynamic behaviors. On the other hand, they run in multiple modes through switches between different operational modes and display event-driven discrete behaviors. Moreover, both continuous and discrete dynamic behaviors are interactive [5]-[7].

3. More uncertain environment of operation. In a MG, there exist many distributed generation units whose power outputs are highly dependent on natural renewable energies. Such renewable energy resources often offer an intermittent and uncertain power supply. Moreover, MG offers services to end users whose demands are also usually unpredictable. These factors lead to an uncertain operational environment of MG.

4. Multi-mode operation. In a MG, many distributed generation units usually run in multiple modes of operation. In addition, some distributed energy resources can be also allowed to embed into or withdraw from the system at any time according to some control commands, which is so called as "plug-and-play." And this also results in the multiple modes of operation.

To meet the above listed challenges, a multi-agent technology is considered as preferred control scheme for MG, because it can provide the following desirable properties [8]-[11].

1. Autonomy; In multi-agent system (MAS), each agent can manage the behaviors of individual unit mostly autonomously in a cooperative or competitive environment. And the controls of various agents can implement asynchronously and in parallel. Therefore, the multi-agent technology can provide support to design efficient smart control for such a multi-source interconnected complex MG.

2. Reactivity; In multi-agent system, agents can perceive environment, and respond adequately to the variable and uncertain environment. It means that the multi-agent based control has strong adaptability to uncertain environment of operation.

3. Social ability and pro-activeness; In multi-agent system, many agents are grouped together and depend on each other to form a community that cooperates to achieve the goals of individuals and system. In case one agent fails, other agents may adapt and continue the system function through the interactions among agents. And faults of one or several agents can not make the overall system useless. It means that the multi-agent based control has strong robustness to large disturbances.

In addition, considering the hybrid dynamic behaviors and multiple modes of operation, a smart control scheme for a $\mathrm{MG}$ 
requires not only the continuous controllers to regulate dynamic behaviors of units, but also the discrete control strategies to coordinate switching behaviors of multi-mode operations. It must be emphasized that there is a real-time interactive cooperation between discrete and continuous controls. In this case, the smart control should be designed as hybrid control. Hybrid control theory is the evolution of multi-mode control that provides new capabilities in controlling complex hybrid systems [12]. As an effective means, the technology has already been proposed in the area of power system control, and a few contributions have been made in [13]-[16].

In this paper, considering the hybrid dynamic behaviors and hierarchical control requirements, the smart control for autonomous MG is proposed as a multi-agent based hierarchical hybrid control. The research is decomposed into several stages:

In the first stage, we design the multi-agent based hierarchical hybrid control scheme, which contains an upper level agent in a centralized control manner, several middle level agents in a coordinated control manner, and many lower level unit agents in a decentralized control manner. And the goals of smart control are achieved via designing control strategies in the hierarchical multi-agent system, which contains continuous unit control strategies, discrete coordinated control strategies, energy optimization management strategies and their interactions based on communications.

In the next stage, the upper level energy management agent is studied. The agent is mainly responsible for energy management of the whole system to maximize economical and environmental benefits. We mainly focus on the energy management strategies by using the multi-objective optimization (MOO) method [17]. The management strategies are also able to respond adequately to switching of multiple modes.

In the third stage, the middle level coordinated control agents are designed by regions. Namely, there is a middle level agent in each region that is responsible for operational mode switching of this region to maintain secure voltages. We mainly focus on the switching strategies for operational mode including coordinated strategies between unit agents and logic coordinated control commands between middle level and lower level agents.

In the final stage, the control strategies for the lower level unit control agents are presented. Each unit agents are mainly responsible for complying with the commands from the senior level agents and regulating dynamic performance of respective unit. We focus on the continuous control strategies of respective unit agent. The control strategies for different kinds of unit agents are very different, which are highly dependent on the dynamic characteristics and operational modes of respective unit agents. Here, we present a generality design idea of continuous control strategies for various unit agents.

\section{The Multi-Agent Based Hierarchical Hybrid CONTROL SCHEME}

The framework of hierarchical multi-agent system is constructed as shown in Fig. 1, and the architecture of multi-agent based hierarchical hybrid control for an autonomous $M G$ is shown as Fig. 2.

The architecture of the agents and the interaction among them are the two main aspects in a multi-agent system. In this paper, there are three hierarchies of agents, and the architectures of different hierarchical agents and the interaction among them are designed as follows:

The lower level unit control agent is designed as a hybrid agent, which consists of both reactive and deliberative layer.

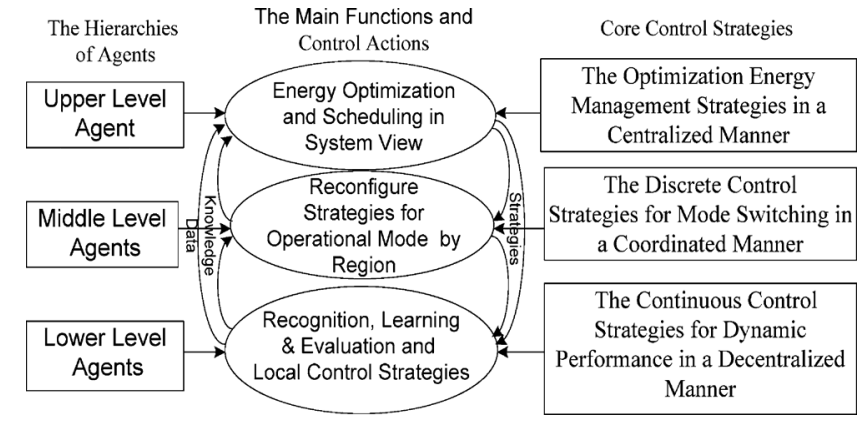

Fig. 1. Framework of hierarchical multi-agent system.

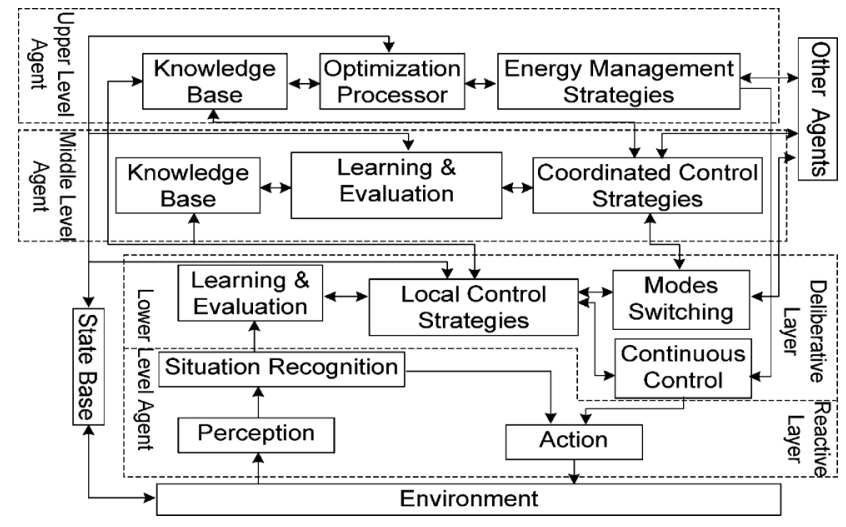

Fig. 2. Architecture of hierarchical multi-agent based on hybrid control system

The reactive layer that is defined as "perception and action" has priority to respond quickly to emergencies of environment. Such as, the reactive layer of renewable resource unit agent can perceive the sudden change of nature conditions so as to determine whether it should act immediately to ask for switch of operational mode. And the deliberative layer that is defined as "belief, desire and intention" has high intelligence of controlling or planning the behaviors of agent so as to achieve its desire or intention. In this paper, versus the hybrid dynamic behaviors of distributed energy resource, the control strategies of the deliberative layer in unit agent are designed as hybrid control, which contain both discrete and continuous controls corresponding to mode switching and continuous running state respectively.

The middle level coordinated control agent is designed as a deliberative agent. Its intention is to coordinate switching of operational modes so as to maintain secure voltages. The reconfiguration plans of operational mode are carried out by the coordinated control strategies, which are determined based on the voltage security assessment by using knowledge data and state data.

The upper level energy management agent is also deliberative agent. It can plan the energy management strategies through the optimization process based on knowledge data and state data in order to manage the power assignment of whole autonomous MG.

In the designed multi-agent system, the interactions among agents include both direct agent-to-agent and indirect interactions. Form top to bottom, the power assignments from the upper level agent to the lower level the group of unit agents, and the coordinated control commands for mode switching from the middle level agent to the lower level the group of unit agents are direct interactions. Conversely, the interactions form the lower level agents to the both upper level and middle level agents are indirect interactions based on the environment. In other words, the lower level agents modify the state data of the 


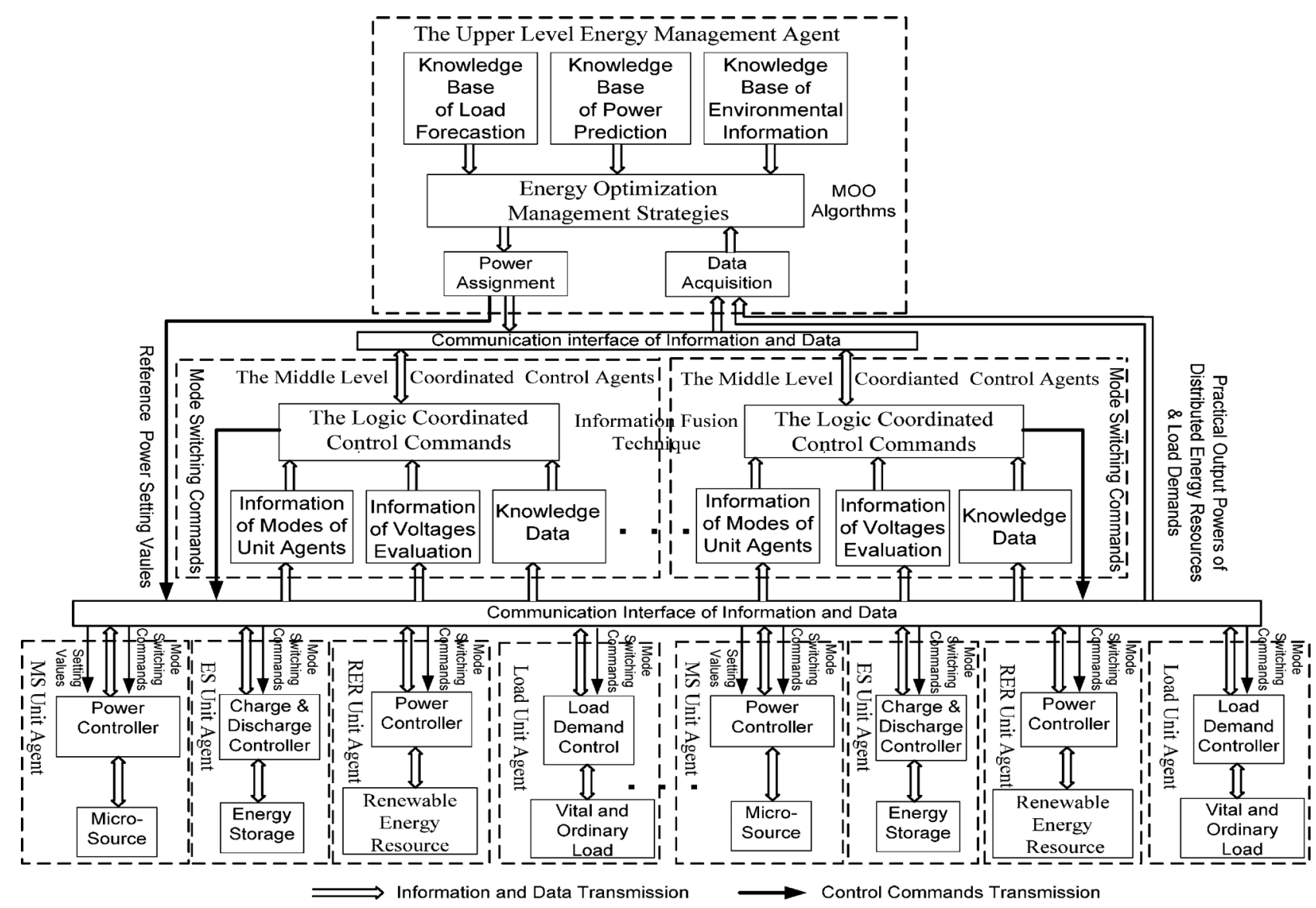

Fig. 3. The structure sketch map of hierarchical multi-agent based hybrid control for an autonomous MG.

environment so as to trigger the change of the control strategies of senior level agents. The interactions between unit agents include both direct and indirect interactions, such as when the cooperation request of a unit agent is responded by another unit agent, this interaction is direct, but when a unit agent modifies another unit agent's environment so as to trigger its reaction, this interaction is indirect.

The architecture sketch map of hierarchical multi-agent hybrid control system for an autonomous MG is shown in Fig. 3 .

\section{The Upper Level Energy Management Agent}

The most important tasks of the upper level agent are to constitute energy management strategies, as well as according to the energy management strategies, to assign generating electricity task to each unit agent of distributed energy resource. Therefore, in this section, the researches are focused on how to establish the energy management strategies and how to implement the power assignment plans through interactive behaviors associated with other agents.

\section{A. The Energy Management Strategies}

1) The Multi-Objective Functions: (1) The cost objective function is constructed as follows

$$
\begin{aligned}
O_{1}=\min \left\{\sum_{i=1}^{n} \sum_{s=1}^{S_{i}} \phi_{\text {is }}[(\right. & h_{i} * F_{\text {is }}\left(P_{\text {DERis }}\right) \\
& \left.\left.+M_{i}\left(P_{\text {DERis }}\right)+\lambda_{\text {is }} C_{\text {sti }}\right]\right\},
\end{aligned}
$$

where $i \in\{1,2, \ldots, n\}$, and $n$ is the number of distributed energy resources in MG. $s \in\left\{1,2, \ldots, S_{i}\right\}$ represent operational mode of i-th unit. $P_{\mathrm{DERis}}$ and $F_{\mathrm{is}}\left(P_{\mathrm{DER} \text { is }}\right)$ denote power output and consumption characteristic function of $i$-th unit in s-th operational mode respectively. $h_{i}$ is the price per unit fuel. Versus renewable energy resources, $h_{i} \equiv 0 . M_{i}\left(P_{\text {DERis }}\right)$ represents maintenance cost, which is deemed in proportion to $P_{\text {DERis }}$. $C_{\text {sti }}$ is the starting cost of i-th unit. $\lambda_{\text {is }} \in[0,1]$, when i-th unit in s-th operational mode is starting, $\lambda_{\text {is }}=1$, otherwise, $\lambda_{\text {is }}=0$. $\phi_{\text {is }} \in[0,1]$, when i-th unit in s-th operational mode is connected to system, $\phi_{\mathrm{is}}=1$, otherwise, $\phi_{\mathrm{is}}=0$.

(2) The objective function of pollution emission is constructed as follows

$$
O_{2}=\min \left\{\sum_{i=1}^{n} \sum_{s=1}^{S_{i}} \sum_{k=1}^{\Lambda} \phi_{\text {is }} \rho_{\text {is }} g_{\text {is }}^{k} P_{\text {DERis }}\right\},
$$

where $k \in\{1,2, \ldots, \Lambda\}$, and $\Lambda$ is the number of species of emission substances in distributed energy resources. $\rho_{\text {is }}$ is the rate of pollution emission. $g_{\mathrm{is}}^{k}$ represents the punishment fee for $\mathrm{k}$-th kind emission. Versus renewable energy resources, $g_{\mathrm{is}}^{k} \equiv 0$. $\phi_{\mathrm{is}} \in[0,1]$ is same meaning as above.

(3) The objective function of network loss

In order to decrease line losses, a distributed energy resource unit should offer service to the nearest user around it as much as possible. For this reason, the objective function is constructed as

$$
O_{3}=\min \left\{\sum_{i=1}^{n} \sum_{s=1}^{S_{i}} \sum_{j=1}^{m} \mu \phi_{i s} d_{i j} R_{i j} \frac{P_{i j s}^{2}+Q_{i j s}^{2}}{U_{i j}^{2}}\right\},
$$

where $j \in\{1,2, \ldots, m\}$, and $m$ is the number of load units. $d_{i j}$ and $R_{i j}$ represent the distance and resistance between i-th unit 
TABLE I

InTERACTIVE BeHAVIORs OF THE ENERGy MANAGEMENT AGENT Associated With Other Agents

\begin{tabular}{|c|c|c|c|c|c|c|c|c|}
\hline \multirow{2}{*}{ Agent } & \multirow{2}{*}{ Behaviors } & \multicolumn{3}{|c|}{ Receive message } & \multicolumn{4}{|c|}{ Send message } \\
\hline & & Performative & Conversation ID & Content & Performative & Conversation ID & Content & Receivers \\
\hline Load agent & LA reconfigure start & - & - & - & Query-ref & Reconfigure & Load demand & EMA \\
\hline (LA) & & Accept proposal & Load control & oad demand & & & & \\
\hline $\begin{array}{ll}\text { Energy } & \text { man- } \\
\text { agement } & \text { agent } \\
\text { (EMA) } & \end{array}$ & $\begin{array}{l}\text { EMA reconfigure } \\
\text { EMA decision } \\
\text { EMA reply }\end{array}$ & $\begin{array}{l}\text { Query-ref } \\
\text { DERAPropose } \\
\quad-\end{array}$ & $\begin{array}{l}\text { Reconfigure } \\
\text { Reply All a } \\
\end{array}$ & $\begin{array}{l}\text { Load demand } \\
\text { sent information }\end{array}$ & $\begin{array}{l}\text { Request } \\
\text { Propose } \\
\text { propose }\end{array}$ & $\begin{array}{l}\text { Reconfigure } \\
\text { EM strategies } \\
\text { Reconfigure }\end{array}$ & $\begin{array}{l}\text { Start new task } \\
\text { Power assignments } \\
\text { Load demand }\end{array}$ & $\begin{array}{l}\text { All DERAs } \\
\text { All DERAs } \\
\text { LA }\end{array}$ \\
\hline $\begin{array}{l}\text { Distributed } \\
\text { energy resource } \\
\text { agent (DERA) }\end{array}$ & $\begin{array}{l}\text { DERA propose } \\
\text { DERA reply }\end{array}$ & $\begin{array}{l}\text { EMARequest } \\
\text { Accept proposal }\end{array}$ & $\begin{array}{l}\text { Reconfigure } \\
\text { Local control }\end{array}$ & $\begin{array}{l}\text { Start new task } \\
\text { Power output }\end{array}$ & Propose & Reply & All agent information & $\begin{array}{l}\text { EMA } \\
-\end{array}$ \\
\hline
\end{tabular}

and j-th load unit respectively. $\mu$ denotes electrovalency. $P_{i j s}$ and $Q_{i j s}$ denote the transmitted power from i-th unit agent to the $\mathrm{j}$-th load agent in s-th operational mode. $U_{i j}$ is the rating line voltage. In order to limit line losses, if $d_{i j} \geq d_{\text {enactment }}, P_{i j s}$ and $Q_{i j s}$ are denoted as zero. $\phi_{i s} \in[0,1]$ is same meaning as above.

2) The Multi-Objective Optimization: The energy management problem is formulated as the following multi-objective optimization function satisfying with the constraint

$$
\begin{aligned}
& \min O=\gamma_{1} O_{1}+\gamma_{2} O_{2}+\gamma_{3} O_{3} \\
& \text { s.t. } \sum_{i=1}^{N_{G}} P_{G i}+\sum_{i=1}^{N_{s t}}\left[P_{s t . d i}-P_{s t, c i}\right]=\sum_{i=1}^{m} P_{\text {loadi }}+P_{\text {loss }}
\end{aligned}
$$

where $\gamma_{1}, \gamma_{2}$ and $\gamma_{3}$ are the weight coefficients of each objective function respectively. $N_{G}+N_{s t}=n$ is the number of distributed energy resource agents. $P_{\text {loadi }}$ is the power demand of i-th load unit agent. $P_{\text {loss }}$ is the line loss of whole system. In (4), when a storage unit operates in discharging mode $P_{s t, c i}=0$; otherwise, $P_{s t, d i}=0$.

Based on (4), by using the particle swarm optimization method, the energy management strategies can be determined, as well as the power assignment plans can be obtained.

\section{B. The Interactive Behaviors Between Energy Management Agent With Other Agents}

The power assignment plans are implemented through the interactive behaviors of energy management agent associated with other agents based on foundation for intelligent physical agents, agent communication language (FIPA-ACL) in Java agent development framework (JADE). FIPA-ACL messages are characterized by performative, conversation ID, content and receivers. The interactive behaviors based on FIPA-ACL messages are described in Table I.

\section{The Middle Level Coordinated Control Agents}

In autonomous mode, the voltages of $\mathrm{MG}$ must be maintained by all distributed energy resources. As that the MG system usually runs under different conditions to meet the changes of load, environment and social, the intelligent reconfigure strategies are required to switch operational mode so as to meet different changes and maintain secure voltages. With respect to different architecture of $\mathrm{MG}$, the reconfigure strategies of operational mode should be very different. In this paper, an example of autonomous $\mathrm{MG}$ is shown in Fig. 4, which contains a renewable PV source, a fuel microsource, a storage battery and a group of loads. Here, the switching of operational mode is carried

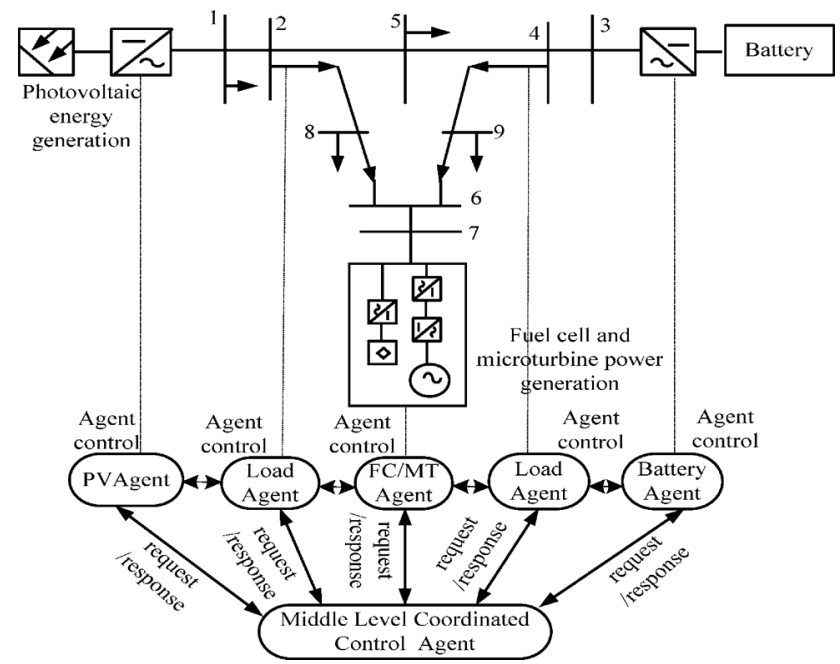

Fig. 4. The diagram of the investigated autonomous MG.

out by the coordinated control strategies between unit agents in Section IV-A and the logic coordinated control commands between middle level and lower level agents in Section IV-B.

\section{A. Coordinated Control Strategies of Operational Mode Between Different Unit Agents}

The sketch map of the reconfigure strategies is shown in Fig. 5, where the mode switching process in respective unit agent is described based on Petri-net, and corresponding descriptions of places and transitions are given in Tables II-V respectively.

On Petri-net model, the mode switching process of unit agent depends on not only event-driven discrete behavior of itself, but also interactive behaviors associated with other agents. Such as storage unit agent usually ask for switching its charging or discharging state through interactive behaviors with other agents. With respect to renewable source unit, because of its uncertain power output, its power supply need be supported by other agents through interactive behaviors. When one unit agent need change mode by interactive behaviors, it can send a request to other agents. If other agents reply it, its mode switching can be implemented. The interactive behaviors regarding mode switching between two agents are implemented based on FIPA-ACL messages that are described in Table VI.

\section{B. The Logic Coordinated Control Commands Between Middle Level and Lower Level Agents}

The logic coordinated control commands will be determined based on information fusion technique of following characteristic parameters. 


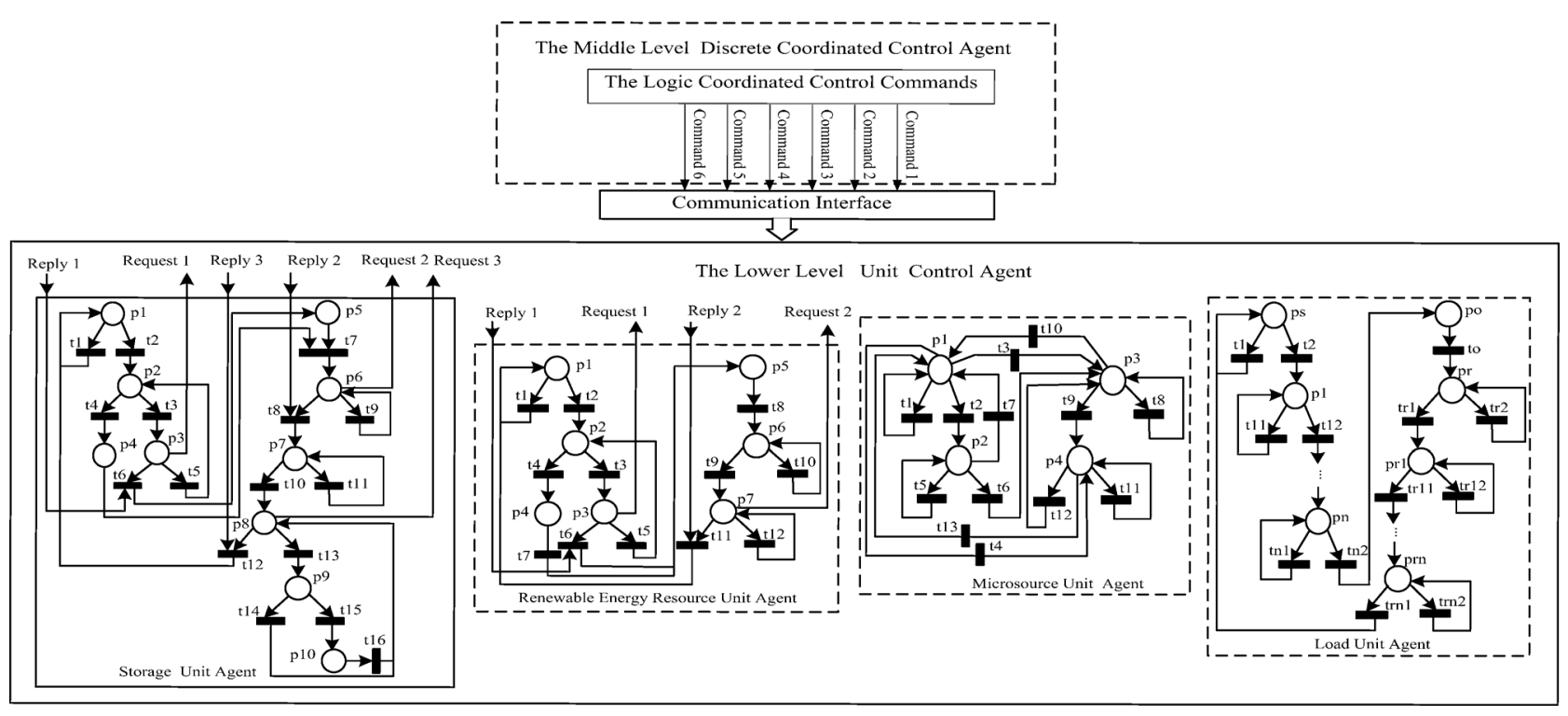

Fig. 5. The coordinated control strategies for operating mode.

TABLE II

Description of Places and Transitions in Storage Unit Agent

\begin{tabular}{|c|c|}
\hline $\begin{array}{c}\text { Places/ } \\
\text { Transitions }\end{array}$ & Description \\
\hline $\mathrm{p} 1$ & Discharging state \\
\hline p2 & $\begin{array}{l}\text { Discharging state with insufficient state of charge } \\
\text { (SOC) }\end{array}$ \\
\hline p3 & $\begin{array}{l}\text { Discharging state with insufficient SOC while re- } \\
\text { questing other agents for stopping discharging }\end{array}$ \\
\hline p4 & Stopping state with the lowest critical SOC \\
\hline p5 & Stopping state with insufficient SOC \\
\hline p6 & $\begin{array}{l}\text { Stopping state while requesting other agents for } \\
\text { charging }\end{array}$ \\
\hline p7 & Charging state \\
\hline p8 & $\begin{array}{l}\text { Charging state with sufficient SOC while requesting } \\
\text { other agents for discharging }\end{array}$ \\
\hline p9 & Charging state with sufficient SOC \\
\hline p 10 & Stopping state with the highest critical SOC \\
\hline $\mathrm{t} 1$ & SOC is sufficient \\
\hline $\mathrm{t} 2$ & SOC is insufficient \\
\hline $\mathrm{t} 3$ & SOC is not the lowest critical value \\
\hline $\mathrm{t} 4$ & SOC is the lowest critical value \\
\hline t5 & Other agents don't reply \\
\hline t6 & Other agents reply \\
\hline t7 & Storage unit agent prepares charging \\
\hline $\mathrm{t} 8$ & Other agents reply \\
\hline t9 & Other agents don't reply \\
\hline $\mathrm{t} 10$ & SOC is sufficient \\
\hline t11 & SOC is insufficient \\
\hline $\mathrm{t} 12$ & Other agents reply \\
\hline $\mathrm{t} 13$ & Other agents don't reply \\
\hline $\mathrm{t} 14$ & SOC is not the highest critical value \\
\hline $\mathrm{t} 15$ & SOC is the highest critical value \\
\hline t16 & $\begin{array}{l}\text { Storage unit agent requests other agents for discharg- } \\
\text { ing }\end{array}$ \\
\hline
\end{tabular}

1) Characteristic Parameters Regarding Voltage Security: Here, the voltage drop of nodes acts as characteristic parameter of voltage security and can be formulated as follows

$$
C_{i h}^{l}(V)=\frac{V_{i}^{l}-V_{i 0}}{V_{i 0}}, \quad\left(i \in 1,2, \ldots, v_{h}\right),
$$

where $v_{h}$ is the number of nodes in h-th middle level agent colony. $V_{i 0}$ is rating voltage of $\mathrm{i}$-th node. $V_{i}^{l}$ is the transient voltage of $i$-th node at l-th timing.
TABLE III

Description of Places and TRansitions in Renewable Resource Agent

\begin{tabular}{cl}
\hline \hline $\begin{array}{c}\text { Places/ } \\
\text { Transitions }\end{array}$ & \multicolumn{1}{c}{ Description } \\
\hline $\mathrm{p} 1$ & MPPT state at the normal condition \\
$\mathrm{p} 2$ & Output power decreasing state \\
$\mathrm{p} 3$ & Output power decreasing state while requesting other \\
$\mathrm{p} 4$ & agents for support of power supply \\
$\mathrm{p} 5$ & Lopping operating state \\
$\mathrm{p} 6$ & Output power increasing state \\
$\mathrm{p} 7$ & MPPT state while requesting other agents for stopping \\
$\mathrm{t} 1$ & support of power supply \\
$\mathbf{t} 2$ & Natural energy is sufficient \\
$\mathbf{t} 3$ & Natural energy is insufficient \\
$\mathbf{t} 4$ & Natural energy is not the lowest critical value \\
$\mathbf{t 5}$ & Other agents don't reply \\
$\mathbf{t} 6$ & Other agents reply \\
$\mathbf{t} 7$ & Natural energy satisfies threshold value condition again \\
$\mathbf{t} 8$ & Natural energy is increasing \\
$\mathrm{t} 9$ & Output power capacity is sufficient \\
$\mathrm{t} 10$ & Output power capacity is insufficient \\
$\mathrm{t} 11$ & Other agents reply \\
$\mathrm{t} 12$ & Other agents don't reply \\
\hline
\end{tabular}

2) The Security Assessment Indexes Based on Information Fusion Technique of D-S Evidence Theory: In order to determine security assessment indexes, here, we propose the information fusion technique of D-S evidence theory.

Firstly, we construct the basic probability functions based on the characteristic parameters as follows

$$
m_{i h}^{l}(V)=C_{i h}^{l}(V) /\left[C_{i h}^{l}(V)+\left(1-\gamma_{i h v}^{l}\right)\left(1-\alpha_{i h v} \beta_{i h v}\right)\right],
$$

where $m_{i h}^{l}(V)$ denotes basic probability assignments of voltages on i-th node at 1-th timing in h-th local region. $\gamma_{i h v}^{l}$ are weight coefficients of voltages. These weight coefficients are limited to between 0 and $1 . \alpha_{i h v}$ and $\beta_{i h v}$ are maximum voltages and relative voltages among all timings on i-th node respectively.

According to the timing sequences $l \in\{1,2, \ldots q\}$ and all node $i \in\left\{1,2, \ldots, v_{h}\right\}$, the basic probability assignments 
TABLE IV

Description of Places and Transitions in Microresource Agent

\begin{tabular}{|c|c|}
\hline $\begin{array}{l}\text { Places/ } \\
\text { Transitions }\end{array}$ & Description \\
\hline $\mathrm{p} 1$ & Rating operating state at the normal condition \\
\hline $\mathrm{p} 2$ & Low voltage operating state \\
\hline p3 & Hot standby state \\
\hline $\mathrm{p} 4$ & Cold standby state \\
\hline tl & Maintain running \\
\hline $\mathrm{t} 2$ & $\begin{array}{l}\text { Receive control command for switching into low voltage } \\
\text { operating state }\end{array}$ \\
\hline $\mathrm{t} 3$ & $\begin{array}{l}\text { Receive control command for stopping running and } \\
\text { switching into hot standby state }\end{array}$ \\
\hline t4 & $\begin{array}{l}\text { Receive control command for stopping running and } \\
\text { switching into cold standby state }\end{array}$ \\
\hline $\mathrm{t} 5$ & Maintain low voltage operating \\
\hline t6 & $\begin{array}{l}\text { Receive control command for stopping running and } \\
\text { switching into hot standby state }\end{array}$ \\
\hline $\mathrm{t} 7$ & $\begin{array}{l}\text { Receive control command for returning into rating oper- } \\
\text { ating state }\end{array}$ \\
\hline t8 & Maintain hot standby state \\
\hline t9 & $\begin{array}{l}\text { Receive control command for switching into cold } \\
\text { standby state from hot standby }\end{array}$ \\
\hline $\mathrm{t} 10$ & $\begin{array}{l}\text { Receive control command for returning into rating oper- } \\
\text { ating state }\end{array}$ \\
\hline $\mathrm{t} 11$ & Maintain cold standby state \\
\hline $\mathrm{t} 12$ & $\begin{array}{l}\text { Receive control command for switching into hot standby } \\
\text { state from cold standby }\end{array}$ \\
\hline $\mathrm{t} 13$ & $\begin{array}{l}\text { Receive control command for returning into rating oper- } \\
\text { ating state from cold standby }\end{array}$ \\
\hline
\end{tabular}

TABLE V

DESCRIPTION OF Places AND TRANSITIONS IN LOAD AGENT

\begin{tabular}{cl}
\hline \hline $\begin{array}{c}\text { Places/ } \\
\text { Transitions }\end{array}$ & \multicolumn{1}{c}{ Description } \\
\hline ps & Load state at the normal condition \\
p1 & The state at load shedding for the first time \\
pn & The state at the load shedding for the last time \\
po & The state without the ability of load shedding \\
pr & The readiness state for load restoration \\
pr1 & The state at load restoration for the first time \\
prn & The state at load restoration for the last time \\
t1 & Load voltage are normal \\
t2 & Load voltage overstep their threshold values \\
t11 & Load voltage return normal values \\
t12 & Load voltage still overstep their threshold values \\
tn1 & Load voltage return normal values \\
tn2 & Load voltage still overstep their threshold values \\
to & Load agent is preparing for load restoration \\
$\operatorname{tr} 1$ & Load restored condition is satisfied for the highest-level \\
$\operatorname{tr} 2$ & load \\
$\operatorname{tr} 11$ & Load restored condition is unsatisfied \\
$\operatorname{tr} 12$ & Load restored condition is satisfied again \\
$\operatorname{trn} 1$ & Load restored condition is unsatisfied \\
$\operatorname{trn} 2$ & Load restored condition is satisfied for the lowest-level \\
\hline \hline
\end{tabular}

$m_{i h}^{l}(V)$ are fused based on the fusion criterion of D-S evidence theory. The fusion result is integrated security assessment index of voltage in h-th local region, which is denoted as $\bar{m}_{h}(V)$.

3) The Logic Coordinated Control Commands: When the security assessment index approaches its threshold value, it implies that the voltage is insecure in this region. The threshold value can be enacted in critical working conditions in an offline manner in advance. The threshold value is defined as $\varepsilon_{h, \text { threshold }}>0$. According to whether the threshold is violated, we denote

$$
F_{h}=\bar{m}_{h}(V)-\varepsilon_{h, \text { threshold }},
$$

$$
\begin{aligned}
& \text { if }\left|\bar{m}_{h}(V)\right| \geq \varepsilon_{h, \text { threshold and } \bar{m}_{h}(V)>0,} \\
& F_{h}=\bar{m}_{h}(V)+\varepsilon_{h, \text { threshold }}, \\
& \quad \text { if }\left|\bar{m}_{h}(V)\right| \geq \varepsilon_{h, \text { threshold }} \text { and } \bar{m}_{h}(V)<0 .
\end{aligned}
$$

In light of the size of $F_{h}$, we map it into 6-tuple fuzzy set as $\{\mathrm{NB}, \mathrm{NM}, \mathrm{NS}, \mathrm{PS}, \mathrm{PM}, \mathrm{PB}\}$.

Corresponding to the architecture of $\mathrm{MG}$ as shown in Fig. 4, if original modes of unit agents are storage unit agent: P8, renewable unit agent: P1, fuel microsource unit agent: P2, load unit agent: Ps, then the original mode of the group of unit agents is defined as $\mathrm{M}(8,1,2, \mathrm{~s})$. In this case, the coordinated voltage control commands as follows

No command, if $\left|\bar{m}_{h}(V)\right|<\varepsilon_{h, \text { threshold }}$;

Command 1: $\mathrm{M}(8,1,2, \mathrm{~s})$ to $\mathrm{M}(1,1,2, \mathrm{~s})$, if $F_{h}$ is $\mathrm{PS}$;

Command 2: $\mathrm{M}(8,1,2, \mathrm{~s})$ to $\mathrm{M}(1,1,1, \mathrm{~s})$, if $F_{h}$ is $\mathrm{PM}$;

Command 3: $\mathrm{M}(8,1,2, \mathrm{~s})$ to $\mathrm{M}(1,1,1,(1,2 \ldots \mathrm{n}))$, if $F_{h}$ is $\mathrm{PB}$;

Command 4: $\mathrm{M}(8,1,2, \mathrm{~s})$ to $\mathrm{M}(10,1,2, \mathrm{~s})$, if $F_{h}$ is NS;

Command 5: $\mathrm{M}(8,1,2, \mathrm{~s})$ to $\mathrm{M}(10,1,3, \mathrm{~s})$, if $F_{h}$ is $\mathrm{NM}$;

Command 6: $\mathrm{M}(8,1,2, \mathrm{~s})$ to $\mathrm{M}(10,5,3, \mathrm{~s})$, if $F_{h}$ is NB.

The interactive behaviors regarding logic coordinated control commands between middle level and lower level agents are similar to Table VI.

\section{The Lower Level Unit Control Agents}

The design of continuous control strategies for the unit agents is highly dependent on their operational modes and dynamic characteristics, which is very different issue. However, in this section, we present a generality design idea of continuous control strategies for various distributed generation unit agents. The continuous control strategies of distributed generation units are usually divided into two kinds: grid-following control and grid-forming control. The grid-following control is usually selected as the control strategies of the non-dispatchable resources, which mainly includes MPPT control for the renewable energy resource units, V-Q control for the dc resource units and $\mathrm{P}-\mathrm{Q}$ control. The grid-forming control is generally employed as the control strategies of the dispatchable resources, which mainly includes $\mathrm{f}-\mathrm{V}$ control and load sharing based on droop characteristics. In an autonomous $\mathrm{MG}$, at least one or more dispatchable distributed generation units actively participate in grid stabilization and voltage regulation, usually $\mathrm{f}-\mathrm{V}$ control are employed in such unit as shown in Fig. 6. And other non-dispatchable units ordinarily use P-Q control based on the pre-specified reference values as shown in Fig. 7.

Beside the control strategies need be designed for the continuous control, another important issue is how to select appropriate control algorithm for the controller to deal with robust stabilization problem at multi-mode switching scenarios. As an optimal means, the $\mathrm{H}_{\infty}$ robust control method based on multiply Lyapunovs can effectively solve the multi-mode stabilization problem. The method had been introduced in detail in the author's previous contribution [16]. Taking consideration of the paper length, here we will not repeat it.

\section{Simulation STUDiES}

In the researched autonomous $\mathrm{MG}$ as shown in Fig. 4, the single-master operation (SMO) approach is used, where the battery unit acts as the "master-VSC" in $\mathrm{f}-\mathrm{V}$ control mode, and the FC/MT, PV units is dynamically controlled in P-Q mode.

The Case 1: The Load Following Performance: Three distributed generation unit agents offer power supply for the loads 
TABLE VI

INTERACTIVE BeHAVIORS BetweEn Two Unit Agents

\begin{tabular}{|c|c|c|c|c|c|c|c|c|}
\hline \multirow{2}{*}{ Agent } & \multirow{2}{*}{ Behaviors } & \multicolumn{3}{|c|}{ Receive message } & \multicolumn{4}{|c|}{ Send message } \\
\hline & & Performative & Conversation ID & Content & Performative & Conversation ID & Content & Receivers \\
\hline Unit agent I (UAI) & $\begin{array}{l}\text { UAI reconfigure start } \\
\text { UAI reply }\end{array}$ & Accept proposal & -1 Switch control & Mode switch & $\begin{array}{l}\text { Request } \\
\text { Inform }\end{array}$ & $\begin{array}{l}\text { Reconfigure } \\
\text { Accept proposal }\end{array}$ & $\begin{array}{l}\text { Mode switch } \\
\text { Mode switch }\end{array}$ & $\begin{array}{l}\text { UAII } \\
\text { UAII }\end{array}$ \\
\hline Unit agent II (UAII) & $\begin{array}{l}\text { UAII propose } \\
\text { UAII inform }\end{array}$ & $\begin{array}{l}\text { UAIRequest } \\
\text { UAIInform }\end{array}$ & $\begin{array}{l}\text { Reconfigure } \\
\text { Accept proposal }\end{array}$ & $\begin{array}{l}\text { Mode switch } \\
\text { Mode switch }\end{array}$ & Propose & Reply & gent information & n UAI \\
\hline
\end{tabular}

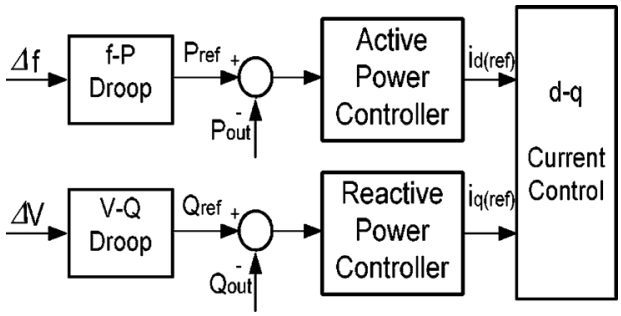

Fig. 6. f-V control strategy.

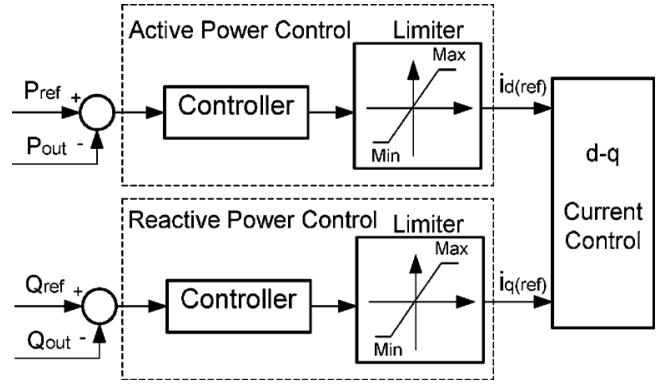

Fig. 7. P-Q control strategy.
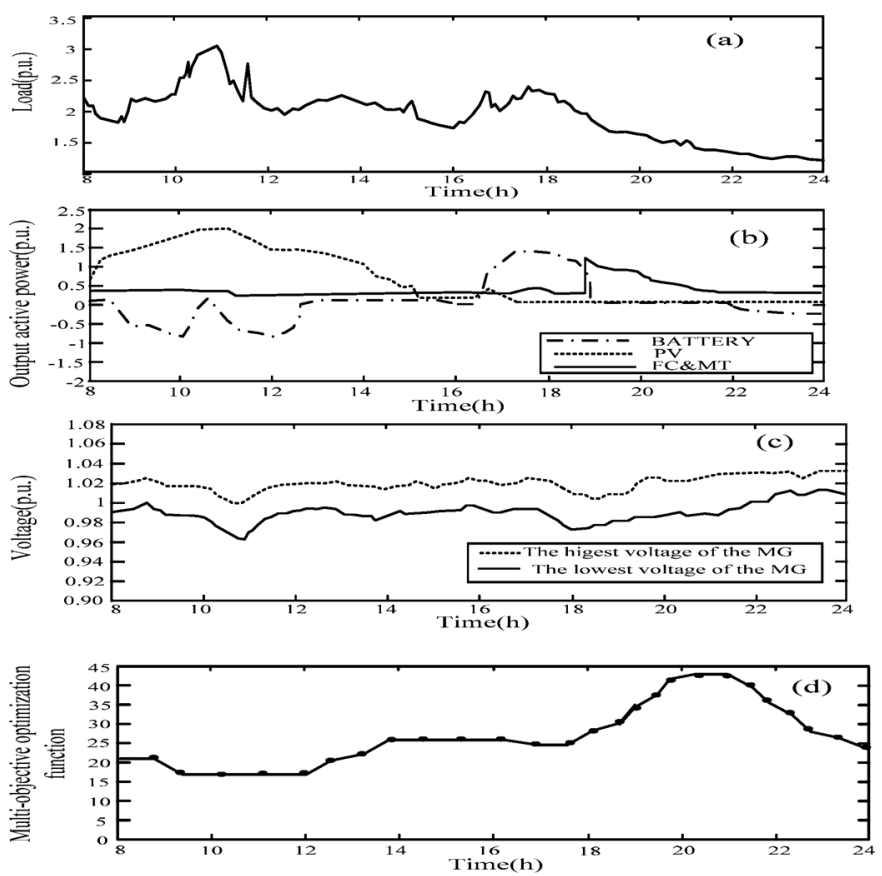

Fig. 8. Load following performance in the case 1.

as shown in Fig. 8(a). The load following performance under the proposed hybrid control is shown in Fig. 8(b) and (c).

Fig. 8(a) is load curve from 8.00 to 24.00 during a day. And Fig. 8(b) shows the optimal active power outputs of three distributed generation unit agents. From Fig. 8(b), it can be seen that PV unit agent runs in MMPT mode as far as possible. Only
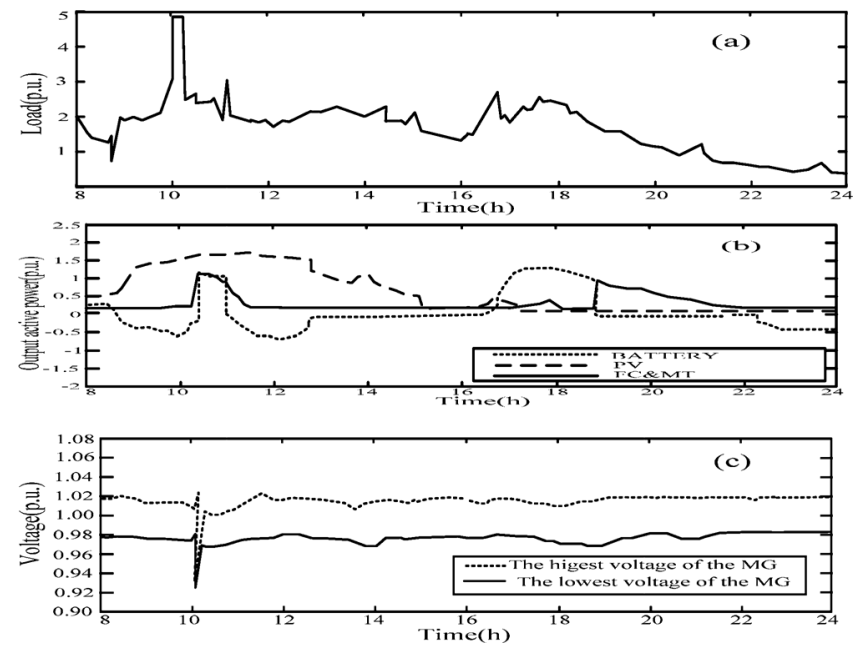

Fig. 9. The responses under a large load disturbance in the case 2 .

after 17.00, due to there is no solar energy, the PV unit agent stops operating. During all of the simulation time, besides the mode of no operation, the battery unit agent is switched between both discharging and charging modes to match disequilibrium powers. And during most of the time, the FC/MT unit agent operates in low voltage mode to reduce operational cost as far as possible. The above power assignments among unit agents indicate that the proposed hybrid control can guarantee the operating cost of the system as small as possible. Fig. 8(c) displays the highest and lowest voltage performance of the autonomous MG. In the Fig. 8(c), it can be seen that during all of the simulation time, the voltage are controlled between 0.98 p.u. and 1.02 p.u., and the fluctuation value is limited in the range of $\pm 2 \%$ of rating value. It indicates that the hybrid control contributes to maintain better voltages and load following performance. Fig. 8(d) displays the multi-objective optimization performance under the load demand.

The Case 2: The Performance Under Load Disturbance: The purpose of the case 2 is to verify the autonomous MG's control performance under a lager load disturbance. Fig. 9 shows the load curve, the optimal active power outputs of three distributed generation unit agents and voltage responses respectively.

When $\mathrm{t}=10 \mathrm{~h}$, a transient load leads to about 100 percent of increasing on the load. This moment, the voltages of MG drop to 0.92 p.u. In order to maintain secure voltages, the middle level coordinated control agent sends control commands to switches FC\&MT unit agent to rating operation state, and to switch battery unit agent to discharging state. When loads return to normal state, the operating situations of distributed generation unit agents are similar to the case 1 .

The Case 3: The Performance Under Unplanned Islanding: It is well known that MG can run in both grid-connected and islanded modes of operation. An unplanned disconnection from main grid usually is regarded as the most severe test to 

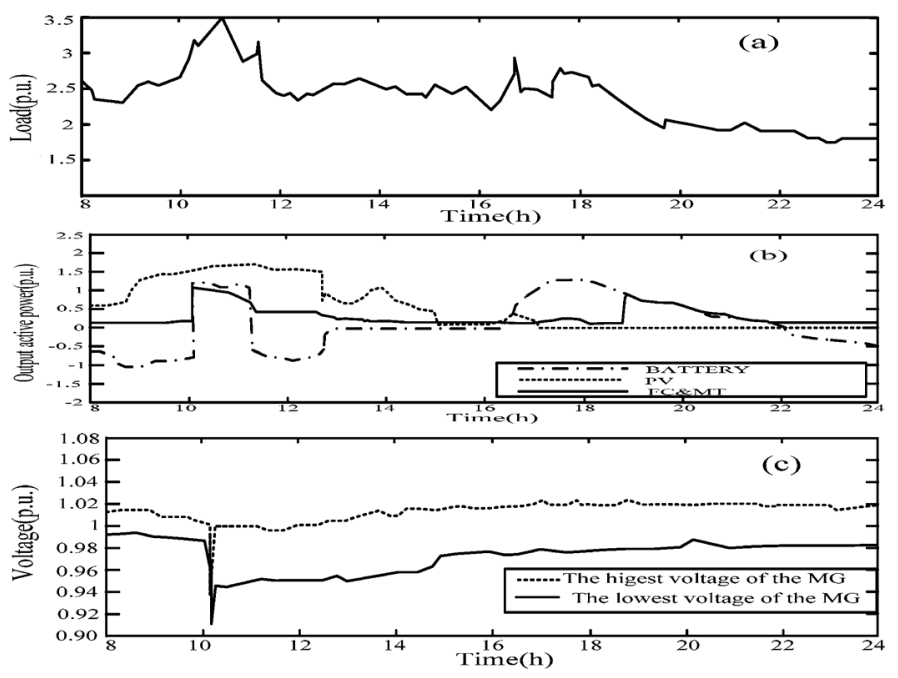

Fig. 10. The responses under unplanned islanding in the case 3 .

the islanded MG. The purpose of the case 3 is to investigate MG's control performances during unplanned islanding. The unplanned islanding occurs at $\mathrm{t}=10 \mathrm{~h}$.

Fig. 10 shows the load curve, the optimal active power outputs of three distributed generation unit agents and voltage responses respectively at the unplanned islanding scenario. From Fig. 10, at islanding moment, voltages drop to 0.91 p.u., in order to maintain secure voltages, the middle level coordinated control agent switches the FC\&MT unit agent to rating operation state, and switches battery unit agent to discharging state. Compared with the case 2, both FC\&MT and battery unit agents keep the switched states longer period of time in the case 3 . The voltages are finally controlled between 0.95 p.u. and 1.02 p.u.

\section{CONCLUSION}

In this paper, a main contribution is that a multi-agent based hierarchical hybrid control is proposed for autonomous MG. In particular, in the hybrid control scheme, the intelligent reconfigure strategies of operational mode are established via Petri nets and the information fusion technique, which is rather innovative. Simulation results show that the proposed hybrid control can maintain secure voltages, as well as maximize economical benefits for an autonomous MG.

\section{REFERENCES}

[1] C. L. Smallwood, "Distributed generation in autonomous and non-autonomous microgrids," in Proc. Rural Elect. Power Conf. IEEE 2002, pp. D1/1-D1/6.

[2] F. Katiraei, M. R. Iravani, and P. W. Lehn, "Microgrid autonomous operation during and subsequent to islanding process," IEEE Trans. Power Del., vol. 20, pp. 248-257, 2005.

[3] A. R. Yasser and E. S. Ehab F, "Adaptive decentralized droop controller to preserve power sharing stability of paralleled inverters in distributed generation microgrids," IEEE Trans. Power Electron., vol. 23, pp. 2806-2816, 2008.
[4] E. Barklund, N. Pogaku, M. Prodanovic, C. H. Aramburo, and T. C. Green, "Energy management in autonomous microgrid using stabilityconstrained droop control of inverters," IEEE Trans. Power Electron., vol. 25, pp. 2346-2352, 2008.

[5] W. Wang, X. Bai, W. Zhao, J. Ding, and Z. Fang, "Hybrid power system model and the method for fault diagnosis," in Proc. IEEE/PES Transm. Distrib. Conf. Exhib., Dalian, China, 2005, Asia and Pacific.

[6] L. Gao, Z. Jiang, and R. A. Dougal, "An actively controlled fuel cell/ battery hybrid to meet pulsed power demands," J. Power Sources, vol. 130, pp. 202-207, 2004.

[7] K. S. Jeong, W. Y. Lee, and C. S. Kim, "Energy management strategies of a fuel/battery hybrid system using fuzzy logics," J. Power Sources, vol. 145, pp. 319-326, 2005.

[8] S. D. J. Mcarthur et al., "Multi-agent systems for power engineering applications, Part I: Concepts, approaches, and technical challenges," IEEE Trans. Power Syst., vol. 22, pp. 1743-1752, 2007.

[9] S. D. J. Mcarthur et al., "Multiagent systems for power engineering applications, Part II: Technologies, standards, and tools for building multiagent systems," IEEE Trans. Power Syst., vol. 22, pp. 1753-1759, 2007.

[10] C. C. Liu, "Agent modeling for integrated power systems," Power Systems Engineering Research Center, Final Project Report, PSERC Publ. Sep. $08-17,2008$

[11] A. L. Dimeas and N. D. Hatziargyrious, "Agent based control for microgrids," in Proc. IEEE PES Gen. Meet., Tampa, FL, Jun. 2007, pp. 24-28.

[12] B. Liu and D. J. Hill, "Comparison principle and stability of discrete impulsive hybrid systems," IEEE Trans. Circuits Syst. I, Reg. Papers, vol. 56, no. 1, pp. 233-245, 2009.

[13] M. Uzunoglu and M. S. Alam, "Dynamic modeling, design, and simulation of a combined PEM fuel cell and ultracapacitor system for standalone residential applications," IEEE Trans. Energy Convers., vol. 21, pp. 23-34, 2006.

[14] K. S. Jeong, W. Y. Lee, and C. S. Kim, "Energy management strategies of a fuel cell/battery hybrid system using fuzzy logics," J. Power Sources, vol. 145, pp. 319-326, 2005.

[15] H. Amin and A. G. Masoud, "Intelligent power management strategy of hybrid distributed generation system," Int. J. Electr. Power Energy Syst., vol. 29, pp. 783-795, 2007.

[16] C. X. Dou, D. L. Liu, X. B. Jia, and F. Zhao, "Management and control for smart microgrid based on hybrid control theory," Elect. Power Compon. Syst., vol. 33, pp. 813-832, 2011.

[17] M. A. Abido, "Environmental/economic power dispatch using multiobjective evolutionary algorithms," IEEE Trans. Power Syst., vol. 18 pp. $1529-1537,2003$.

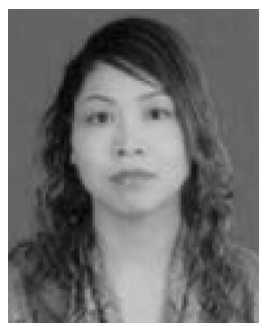

Chun-Xia Dou received the B.Sc., M.Sc., and Ph.D. degrees from Yanshan University, Qinhuangdao, China

She is currently a Professor at the Institute of Electrical Engineering, Yanshan University. Her research interests include intelligent control and hybrid control for large power system, smart grids, microgrids, and complex large systems.

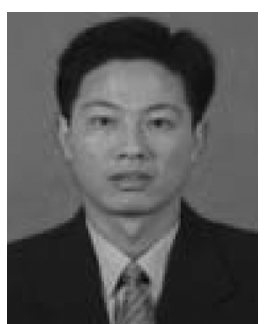

Bin Liu received the M.Sc. degree from East China Normal University, Shanghai, China, and the Ph.D. degree from Huazhong University of Science and Technology, Wuhan, China.

$\mathrm{He}$ is currently a Professor at the Department of Information and Computation Science, Hunan University of Technology, Hunan, China. Now he is also a Queen Elizabeth II Fellow in the Research School of Engineering, The Australian National University, ACT, Australia. His research interests include stability analysis and control for hybrid systems, networked synchronization, and Lie algebra. 